\title{
Ophthalmological lesion in a wild individual of Mountain chicken frog (Leptodactylus fallax)
}

\author{
Andrés Fernández-Loras ${ }^{1,2}$, Bárbara Ferreira ${ }^{3}$, Fidel Fernández-Fernández ${ }^{4}$, \\ Gonçalo M. Rosa ${ }^{2,5,6,7 *}$
}

\begin{abstract}
1. Departamento de Biogeografía y Cambio Global, Museo Nacional de Ciencias Naturales, CSIC, José Gutiérrez Abascal, 2, 28006, Madrid, Spain

2. Durrell Wildlife Conservation Trust, Les Augrés Manor, La Profonde Rue, Trinity, Jersey, Channel Islands, UK (previous affiliation)

3. Faculdade de Medicina Veterinária, Universidade de Lisboa, Avenida da Universidade Técnica Pólo Universitário da Ajuda 1300-477, Lisboa, Portugal.

4. Servicio de Oftalmología, Hospital Mutua de Accidentes de Zaragoza (MAZ), Avda de la Academia General Militar, 74, 50015 Zaragoza, Spain

5.Durrell Institute of Conservation and Ecology, School of Anthropology and Conservation, University of Kent, Canterbury, Kent, CT2 7NR, UK

6. Institute of Zoology, Zoological Society of London, Regents Park, NW1 4RY, London, UK

7. Centre for Ecology, Evolution and Environmental Changes (CE3C), Faculdade de Ciências da Universidade de Lisboa, zip code 1749-016, Lisboa, Portugal.
\end{abstract}

"Correspondência: goncalo.m.rosa@gmail.com

\begin{abstract}
In spite of the amount of anatomical studies that have been made regarding the amphibian eye, relatively little has been written about clinical manifestations or diseases affecting the eye of members of this animal Class. Moreover, the majority of research has focused on ocular diseases or lesions of amphibians kept in captivity. We report on a wild Mountain chicken frog (Leptodactylus fallax), a critically endangered species, with a lesion in the left eye. Additionally, we developed a list of possible differential diagnosis for the ophthalmic lesion. We intend to bridge the available knowledge on this topic and understand the problems affecting wild free ranging individuals.
\end{abstract}

Key Words: amphibian ophthalmology; conservation medicine; corneal edema; corneal healing 


\section{INTRODUCTION}

Although the amphibian eye differs quite sharply from other vertebrates in many aspects of its anatomy, the cornea of adult terrestrial amphibians shows less variation. The eye maintains the same corneal structure as other vertebrates with an outer superficial layer of multicellular corneal epithelium, a collagenous homogenous stroma, a Descemet's membrane, and an endothelium (Williams and Whitaker, 1994). In a healthy cornea all these tissue layers are completely transparent. If both corneal epithelium and/or endothelium become compromised so does their functional ability to refract light, to work as diffusion barriers to the fluids, and act as site of active ion transport, moving by osmosis the water out of the stroma and keeping it in its ideal hydration level (Edelhauser, 2006). As a consequence of barrier and ion pump dysfunction, the corneal stroma becomes edematous, resulting in corneal transparency loss as well as opacity and corneal haze appearance (Edelhauser, 2006).

It is well known that worldwide amphibian populations have been progressively declining in the last years (Stuart et al., 2004; Pounds et al., 2006; Hof et al., 2011). More recently, infectious diseases have been pointed as one of the reasons responsible for that decline and consequently, driven a need for research in the veterinary medicine field, not only in the captive but in the free-ranging populations as well (Williams and Whitaker, 1994; Pounds et al., 2006; Densmore and Green, 2007). Ophthalmology of amphibians kept in captivity is relatively well-studied, and ocular disorders are commonly associated with metabolic or nutritional problems, as well as trauma (Whitaker, 2001; Keller and Shilton, 2002; Densmore and Green, 2007; Kern and Colitz, 2013). However, in free-ranging populations there is a lack of information. Thus, we aim to bridge the information gathered from veterinary findings of ocular disorders in captive populations to the incidences on wild individuals. We report one case study of an ophthalmological lesion diagnosed on a wild individual of the Mountain chicken frog (Leptodactylus fallax).

\section{DESCRIPTION}

The Mountain chicken frog is one of the world's largest anurans (Garcia et al., 2007) and is currently listed as critically endangered ( $\mathrm{Fa}$ et al., 2010). The species was once present in at least five major islands in the Lesser Antilles, but now occurs only on two of them: Dominica and Montserrat (King et al., 2005; Hedges and Heinicke, 2007). The loss of habitat, over-hunting, and the introduction of exotic predators are the main reasons for this species decline (Hedges, 1993). Most recently the chytrid fungus (Batrachochytrium dendrobatidis), a worldwide pathogen and a well-described agent responsible for amphibians' decline (Pounds et al., 2006; Hof et al., 2011; Rosa et al., 2013), is affecting the populations on both islands, pushing the species to the edge of extinction (Malhotra et al., 2007; Rosa and Fernández-Loras, 2012; Tapley et al., 2014).

Whilst conducting surveillance work on the chytridiomycosis outbreak in Montserrat and associated effects on the mountain chicken frog population, an adult $L$. fallax male was first captured 
showing signs of an ocular lesion. The specimen was captured within the transect along the Fairy Walk ghaut $\left(16^{\circ} 45^{\prime} 6.52 " \mathrm{~N}, \quad 62^{\circ} 10^{\prime} 43.08^{\prime \prime} \mathrm{W} 220 \mathrm{~m}\right.$ a.s.I.), an area in the Centre Hills used for regular monitoring of long-term changes in amphibian populations (Garcia et al., 2007) a region where the species was most abundant (Young, 2008). We firstly found the frog on 31 August 2009 late in the evening $(23: 45 \mathrm{~h}$ - 00:10h). The individual was captured by hand using latex gloves, measured, assessed for health status and marked with a PIT (ZooChip, AEG, Germany) tag (small transponder implanted under the skin): tag number L5360; SVL 160 $\mathrm{mm}$; weight $410 \mathrm{~g}$. As part of the research project the animal was sampled for chytrid fungus using skin swabs (MWV100, Tubed Sterile Dryswab $^{\text {TM }}$ Tip, Medical Wire \& Equipment Co, Bath, UK) that were taken for analysis before release. After examination in situ, a photograph was taken to record the ocular lesion and help the diagnosis at a later date. The animal was not taken in captivity for further examination in order to minimise the risk of disease transmission to other animals or locations within the island (Speare et al., 2004).

The ocular lesion - a central round-shaped white opacity on the left eye with a cloudy appearance - was noticeable (Figure 1.A). An inner, more transparent area can also be seen. No other lesions or clinical signs were noticed, besides this ophthalmological unilateral abnormality in the central cornea. A more detail look shows that the typical shape and brightness of Descemet's membrane wrinkles (marked by yellow lines in Figure 1.B) appear in the affected corneal area. Although the aid of a slit lamp could have definitely helped us in exactly locating these wrinkles, unfortunately its use under field conditions was not possible. Nevertheless, we can see how those yellow lines disappear below the opaque area of the corneal outer layers' edema (Figure 1.B), something that, from the authors' point of view, marks those wrinkles as Descemet's membrane ones and not epithelium's. Finally, there was no sign of hypopyon in the anterior chamber, and the iris seemed to be completely normal, neither there was sign of conjunctival hyperemia or of corneal neovascularization.

The individual was recaptured again after 18 days (18 September 2009) in apparent good health and showing no clinical signs or marks of the reported episode. Additionally, it was seen on six additional recaptures until the 7 October 2009, always showing no signs of ophthalmological lesions on the recovered eye. Furthermore, there was no significant weight variation between recapture events. During the course of this study (from August to October 2009) we observed 230 individuals, of which only the previously mentioned frog presented a corneal injury. Thus, the prevalence of occurrence of this ophthalmological lesion in the wild population is about $0.43 \%$. 


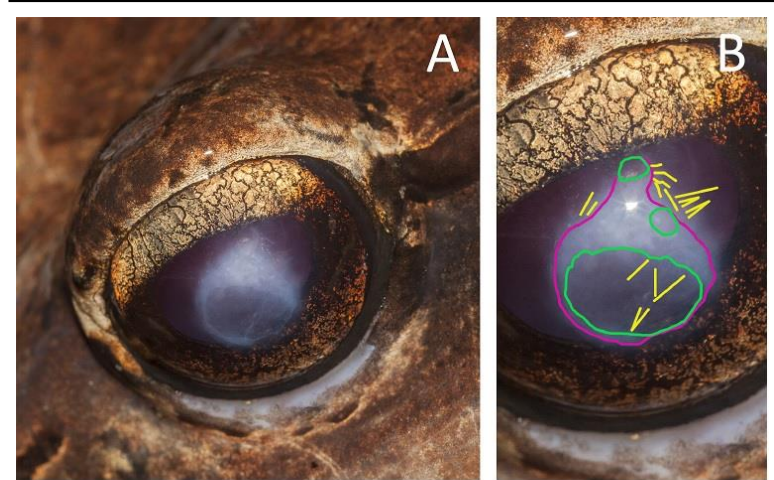

Figure 1. A. Left eye of a wild Mountain chicken frog (Leptodactylus fallax) with a central white opacity. B. More detailed view of the corneal lesion: yellow lines mark the Descemet's membrane wrinkles; green lines surround the more transparent areas; magenta line delimits the more opaque area of the affected cornea. Photos by G. M. Rosa.

\section{DIAGNOSIS}

The pattern of the lesion allows us to formulate a restricted list of differential diagnosis: corneal ulceration is a common one according Stiernke et al. (1995), and Kern and Colitz (2013), taking into account the aspect and location of the lesion, with no additional signs present. However, corneal Purking imagens are somewhat preserved. A standard test with fluorescein should have been done to support the ulcer diagnosis by demarcating the ulceration with loss of epithelium (Whitaker, 2001; Keller and Shilton, 2002), but this was not possible under field conditions.

Corneal edema (swelling within the cornea) is also a possibility due to the cloudy semblance of the cornea, which could be a consequence of a traumatic event in the eye. Another hypothesis is a corneal scar as a result of a trauma, which when involves the stroma causing damage to it, could develop into a corneal leukoma, leaving a permanent corneal opacity associated with the stroma.

Without any additional exams, it is not possible to exclude the diagnosis of corneal lipidosis. This disease is quite common in captive amphibians, especially in females associated with an excessive lipid mobilization during oogenesis. It could also be seen in individuals with nutritional disorders as high cholesterol levels in the diet, which may evolve to hypercholesterolemia, stromal thickening and opacity, ranging from focal and superficial to wide white deep plaques, epithelial surface irregularities, vascularizing keratitis and blindness (Williams and Whitaker, 1994; Whitaker, 2001; Densmore and Green, 2007; Kern and Colitz, 2013). Corneal ulceration can also be produced by the lipid infiltrate, which can induce lipid keratopathy (Whitaker, 2001; Kern and Colitz, 2013). This pathology has been described in several amphibian species, mainly in frogs with three or more years in captivity. (Whitaker, 2001), including the Cuban tree frog (Russell et al., 1990) and a leptodactylid frog, Leptodactylus melanonotus (Dziezyc and Millichamp, 1989). Another type of corneal dystrophy, the rare mineral infiltration within the cornea, may also be considered as a possible diagnostic for this clinical case (Kern and Colitz, 2013).

\section{DISCUSSION}

Physiologically, after a corneal wound involving the stroma there is keratocytes' migration and transformation into active fibroblasts, which increases their reflectivity and the total corneal opacity (Qazi et al., 2010). Moreover there are changes in the composition and arrangement of the extracellular matrix and the collagen fibers. But it would be important to take into account that the new proteoglycans and collagen produced to heal the stromal scar have not the same transparency and strength as the ones 
of the original stroma (Qazi et al., 2010). Therefore depending on the percentage of the cornea affected by a wound or trauma and the efficiency of the repairing process, the eye can or cannot return to its full functionality. Like other terrestrial amphibians, $L$. fallax follows a "sit, wait and grab" predation strategy (Rosa et al., 2012) and depend upon their vision to capture prey. Severe corneal opacities may impair the animal's sight and its prey-catching abilities (Williams and Whitaker, 1994; Whitaker, 2001). Considering the more transparent inner area of our studied individual, and bearing in mind the wrinkled appearance of the Descemet (which indicates an active, not yet cured pathologic process), we could be drawn to conclude that the damaged cornea was maybe recovering and that this complex healing process was eventually taking place. Moreover, the absence of any sign of the lesion in the anuran's eye 18 days after the frog was firstly encountered could lead us to hypothesize that the corneal lesion didn't damage the corneal stroma, resulting in no corneal leukoma.

Usually hypopyon and anterior chamber fibrin deposits are manifestations associated with general septicemia or systemic disease (Millichamp, 1990; Williams and Whitaker, 1994; Whitaker, 2001). Some studies have linked ocular pathologies and abnormalities with infectious diseases (Hale et al., 2005). In case a general septicemia takes place, for example developing from an infectious disease, there might be ocular disorders such as conjunctivitis and corneal involvement that eventually leads to a vascularizing keratitis (Kern and Colitz,
2013). The lack of any of those signs, the fact that the animal appeared to be healthy with normal behaviour, mobility and body weight through all the encounters, and with its eye healed after a few days, could make us think the ocular anomaly described in this study was not caused by a septicemic disorder.

Taking into account all the ocular clinical signs and how the frog's eye was completely recovered in posterior encounters with no sign of corneal opacity, it may be possible to hypothesize a corneal edema with a traumatic origin as the most likely scenario. The edema's reabsorption and complete healing would have resulted in the eye's eventual and full recovery. This fast healing capacity of this species had been previously highlighted by Rosa and Fernández-Loras (2012).

We highlight the importance of reporting cases like this on free-ranging animals, even if being under field conditions makes almost impossible to reach a definite conclusion. From our point of view they generate noteworthy knowledge that may complement and help to understand health issues in captive individuals. Increasing veterinary records of pathologies from wild populations is crucial for conservation medicine and an important element of conservation strategies, particularly for threatened species such as the mountain chicken frog.

\section{Acknowledgements}

This work was carried out during a research project on the chytridiomycosis outbreak that is threatening the Mountain chicken frog in 
Montserrat by Durrell Wildlife Conservation Trust, the Zoological Society of London and Parken Zoo, in collaboration with Montserrat's Forestry Department. We would also like to thank Javier López (Veterinary Manager at Chester Zoo, UK; formerly at Durrell Wildlife Conservation Trust, UK) and Gerardo Garcia (Curator of lower vertebrates and invertebrates at Chester Zoo, UK; formerly at Durrell Wildlife Conservation Trust, UK) for their supervision and outstanding support through the whole research project. Last but not least, we would like to thank Claude Gerald and the Department of Agriculture in Montserrat for permission to work in Montserrat, and especially Kay Bradfield, Sarah-Louise Smith, Calvin "Blacka" Fenton, Lloyd "Lloydie" Martin, James "Scriber" Daly, "Big Lloyd", Philemon "Mappie" Murrain, Jervaine Greenaway, Rudolph Lee, James Boatswain, Glenford James, Taves, Tavez Weekes for their guidance and help in the field during the whole mountain chicken's conservation project. Ultimately, we gratefully acknowledge Lola Brookes and the reviewers for their comments on the manuscript.

\section{REFERÊNCIAS}

Densmore CL, Green DE. 2007. Diseases of amphibians. ILAR J, 48(3): 235-254.

Dziezyc J, Millichamp NJ. 1989. Lipid keratopathy of frogs. Proc 3rd Intl Colloq Pathol Reptil Amphib, 3: 95-96.

Edelhauser HF. 2006. The balance between corneal transparency and edema: the proctor lecture. Invest Ophthalmol Vis Sci, 47(5): 1754-1767.
Fa J, Hedges $B$, Ibéné $B$, Breuil $M$, Powell R, Magin C. 2010. Leptodactylus fallax. The IUCN Red List of Threatened Species. Version 2014.3. www.iucnredlist.org. (Downloaded on March 2015).

Garcia G, Cunningham AA, Horton DL, Garner TWJ, Hyatt A, Hengstberger S, Lopez J, Ogrodowczyk A, Fenton C, Fa JE. 2007. Mountain chickens Leptodactylus fallax and sympatric amphibians appear to be disease free on Montserrat. Oryx, 41: 398-401.

Hale SF, Rosen PC, Jarchow JL, Bradley GA. 2005. Effects of the chytrid fungus on the Tarahumara frog (Rana tarahumarae) in Arizona and Sonora, Mexico. USDA Forest Serv Proc, 36: 407-411.

Hedges, SB. 1993. Global amphibian declines: a perspective from the Caribbean. Biodivers Conserv, 2(3): 290-303.

Hedges SB, Heinicke MP. 2007. Molecular phylogeny and biogeography of West Indian frogs of the genus Leptodactylus (Anura, Leptodactylidae). Mol Phylogenet Evol, 44: 308-314.

Hof C, Araújo MB, Jetz W, Rahbek C. 2011. Additive threats from pathogens, climate and land-use change for global amphibian diversity. Nature, 480(7378): 516-519.

Keller CB, Shilton CM. 2002. The amphibian eye. Vet Clin North Am Exot Anim Pract, 5(2): 261-274.

Kern TJ, Colitz CMH. 2013. Exotic animal ophthalmology. In Gelatt $\mathrm{KN}$, Gilger BC, Kern TJ (ed): Veterinary ophthalmology: Two Volume Set, 5th Edition. Wiley-Blackwell, New Jersey, USA: $1750-1819$. 
King JD, Rollins-Smith LA, Nielsen PF, John A, Conlon JM. 2005. Characterization of a peptide from skin secretions of male specimens of the frog, Leptodactylus fallax that stimulates aggression in male frogs. Peptides, 26(4): 597-601.

Malhotra A, Thorpe RS, Hypolite E, James A. 2007. A report on the status of the herpetofauna of the Commonwealth of Dominica, West Indies. Applied Herpetology, 4(2): 177-194.

Millichamp NJ. 1990. Ocular disease in captive amphibians and reptiles. In Cambre R (ed): Proceeedings of the American Association of Zoo Veterinarians. American Association of Zoo Veterinarians, Philadelphi, USA: 297-301.

Pounds JA, Bustamante MR, Coloma LA, Consuegra JA, Fogden MPL, Foster PN, La Marca E, Masters KL, MerinoViteri A, Puschendorf R, Ron SR, Sánchez-Azofeifa GA, Still CG, Young BE. 2006. Widespread amphibian extinctions from epidemic disease driven by global warming. Nature, 439(7073): 161-167.

Qazi Y, Wong G, Monson B, Stringham J, Ambati BK. 2010. Corneal transparency: genesis, maintenance and dysfunction. Brain Res Bull, 81(2-3):198210.

Rosa GM, Anza I, Moreira PL, Conde J, Martins F, Fisher MC, Bosch J. 2013. Evidence of chytrid-mediated population declines in common midwife toad in Serra da Estrela, Portugal. Animal Conservation, 16(3): 306-315.

Rosa GM, Bradfield K, Fernández-Loras A, Garcia G, Tapley B. 2012. Two remarkable prey items for a chicken: Leptodactylus fallax Müller, 1926 predation upon the theraphosid spider Cyrtopholis femoralis Pocock, 1903 and the colubrid snake Liophis juliae (Cope, 1879). Trop Zool, 25(3): 135-140.

Rosa GM, Fernández-Loras A. 2012. Emergency procedures in the field: a report of wound treatment and fast healing in the giant ditch frog (Leptodactylus fallax). Anim Welfare, 21(4): 559- 562.

Russell WC, Edwards DL, Stair EL, Hubner DC. 1990. Corneal lipidosis, disseminated xanthomatosis, and hypercholesterolemia in Cuban tree frogs (Osteopilus septentrionalis). J Zoo Wildl Med, 21(1): 99-104.

Speare R, Berger L, Skerratt LF, Alford $\mathrm{R}$, Mendez D, Cashins S, Kenyon N, Hauselberger K, Rowley J. 2004. Hygiene protocol for handling amphibians in field studies. Available at http://www.jcu.edu.au/school/phtm/PHT M/frogs/field-hygiene.pdf (accessed March 2015).

Stiernke MM, Watsky MA, Kangas TA, Edelhauser HF. 1995. The establishment and maintenance of corneal transparency. Prog Retin Eye Res, 14(1): 109-140.

Stuart SN, Chanson JS, Cox NA, Young BE, Rodrigues AS, Fischman DL, Waller RW. 2004. Status and trends of amphibian declines and extinctions worldwide. Science, 306(5702): 17831786.

Tapley B, Harding L, Sulton M, Durand $S$, Burton $M$, Spencer J, Thomas R, Douglas T, Andre J, Winston R, George M, Gaworek-Michalczenia M, Hudson M, Blackman A, Dale J, Cunningham AA. 2014. An overview of current efforts to conserve the critically endangered 
mountain chicken (Leptodactylus fallax)

on Dominica. Herpetol Bull, 128: 9-11.

Whitaker BR. 2001. The amphibian eye.

In Wright KM, Whitaker BR (ed):

Amphibian medicine and captive

husbandry. Krieger, Malabar, FL: 245-

252

Williams DL, Whitaker BR. 1994. The amphibian eye: A clinical review. J Zoo Wildlife Med, 25(1): 18-28.

Young RP. 2008. A biodiversity assessment of the Centre Hills, Montserrat. Durrell conservation monograph No.1. Durrell Wildlife Conservation Trust, Jersey, Channel Islands. 